\title{
Improvement of Non-electrical Specialized Computer Hardware Technology
}

\author{
Liqun Tang* \\ College of Computer Science and Technology \\ Harbin Engineering University \\ Harbin,China \\ tangliqun@hrbeu.edu.cn
}

Ran Li

College of Computer Science and Technology

Harbin Engineering University

Harbin,China

tangliqun@hrbeu.edu.cn

\author{
Jianghua Li \\ College of Computer Science and Technology \\ Harbin Engineering University \\ Harbin,China \\ tangliqun@hrbeu.edu.cn
}

\begin{abstract}
Against national colleges for courses in computer hardware technology prevalent education existed fewer class hours, students of different levels, the lack of experimental environment and dedicated supporting materials and other issues in general, combined with years of experience in teaching and scientific research, started from the current social development, corporate demand and students' interests, according to the characteristics of the development of computer hardware technology in the analysis of today's college computer hardware technology courses teaching situation, on the basis of researching professional teaching content, methods and means, this paper proposes a teaching method, which is based on the logic operation combined with calculation thinking, the development of microcomputer system architecture history as the main line, to fully take into account the structural characteristics of various professional fields as computer background, combined with multimedia teaching environment, science summarized and analyzed. This teaching method achieved remarkable results in computer hardware technology courses in teaching.
\end{abstract}

Keywords- computer hardware; prevalent education; teaching reform; multimedia teaching

\section{INTRODUCTION}

Due to the introduction of computer technology, all areas of the world has undergone major changes, the degree of mastering computer technology has been put forward higher requirements in terms of social development, business needs or students. The demand for masters who has the strong skills of compound talents is increasing. Colleges and universities across the country has set computer basic education curriculum for the non-computer professionals, in addition to "Basic Computer Science" and "Program Design Basics" the two main platforms courses, college students in order to improve the comprehensive ability to use a computer, also accept more related computer technology compulsory and elective courses, courses are divided into IT applications and hardware technology lecture; the main part of the information technology is the software applications, the creation of course form is very rich. Howevwe, due to the leading knowledge and a variety of factors hardware technology courses, such as limiting the experimental conditions, the effect of the hardware courses are mostly not very out-standing, a few universities have not even opened general education courses on hardware technology. With the popularity and the development of computer technology, various professional colleges and universities have not the lack of training about the integrated use of computer technology, besides, the number of students who are required with ability to learn and master the computer hardware technology stays on the rise, while the understand and master of hardware technology directly impact to the improvement of comprehensive ability to use a computer.

\section{DEVELOPMENT AND CURRENT SITUATION}

According to statistics, among the national science and engineering college undergraduates, the profession they learn directly related professional computer knowledge nearly 30\%, for example: automation, communications, electronics and other professional; computer knowledge and professional indirectly accounted for $60 \%$, for example: mechanical, energy, transportation, power, management, physics, mathematics, biology, marine, civil engineering and more. This shows that there are nearly $90 \%$ of the professional are inseparable from the use and development of the computer, with the continuous development of the information society, some majors have nothing to do with computer technology, the humanities, law, language, medical and other professions are also integrated into the elements of computer technology, so that people are not fully aware of the age along with the presence of computer technology. Computer technology is mainly divided into two parts: software and hardware, "Computer Hardware Technology" course includes a large number of computer hardware the basic theories and methods, but also be a strong systemic and practical for students practical ability, the ability of engineering practice, development and innovation capacity of particular importance.

"Computer Hardware Technology" as a school nonelectrical professional college students opened a public computer basic course, which aims to help students define the architecture of computer hardware and understand the 
computer external devices from the concept of the basic functions, external characteristics and standards, etc. Besides, the major task is to master computer hardware structure and working principle, including: logic theory, computer works, basic computer instruction, the general concept of assembler design, microprocessor, memory, bus and interface circuit, external equipment. Through this course, students should understand the structure and working principle of computer hardware systems. Also, they should have a general knowledge about the composition of the main components of a computer system and external devices and their commonly used basic functions, features, performance and utility. In addition, students should understand the characteristics of modern microcomputers and future trends of the computer, clearly understand the assembler language programming method. Students take advantage of the hardware and software combination of methods to gain the ability of professional thinking and capacity to analyze and solve problems in the professional or related fields. The course lay the foundation for the development of a computer, to improve students' comprehensive ability to use computer.

According to the 1997 National College Department of Higher Education issued the guide" Opinions about strengthening of non-computer professional computer basic teaching ", have started to create a "Computer Hardware Technology" curriculum, has became the second non-oriented electrical majors offered one technology base level computer courses in the school. 2003 guidance of the Ministry of Education Teaching Computer Science and Technology SubCommittee has issued "on further strengthening the institutions of higher learning basic computer education views" (hereinafter referred to as "Opinion"), the "computer hardware technology base" as the focus of the core curriculum puts forward the basic education requirements. After years of development, according to incomplete statistics, the country has nearly 80 percent of colleges and universities in the University Students in nonelectrical specialty of the course; more than 211 universities in nearly $90 \%$ of non-electric Majors Students in this course; such as: Tsinghua University, National Defense Science, Harbin Institute of Technology, Xi'an Jiaotong University, Beihang University, Beijing Institute of Technology, Dalian University of Technology, Northern Jiaotong University, Tianjin University, Shanghai Jiaotong University, Tongji University, etc., the average number of teaching hours are about 48 hours, including the contents of a certain percentage of the experiment [1]. Due to excessive number of elective general elective institutions of the course students will have a number of limitations, which shows that the degree of college students who love this course.

My school issued early in 1997 according to the Department of Higher Education "opinions" spirit began to create "Computer Hardware Technology" curriculum, the school opened the second level of general education foundation courses in computer technology. The number of Instructors changed from the original one to today three. By the spring semester, the total teaching hours have become two semesters from a single semester in a year. The capacity of selected courses changed from the original 40 to the current limit of 110 people, the number of students who attend the academic lectures increased year by year from the initial 40 people to 600 people. Analyzing this semester elective course which attracted 318 students to attend, $37.7 \%$ of which electricity Majors (4,5,6,8 College) 120 people total. Non-electric Majors 198 people, $62.3 \%$ of the total. The number of elective courses in various colleges in Figure 1.

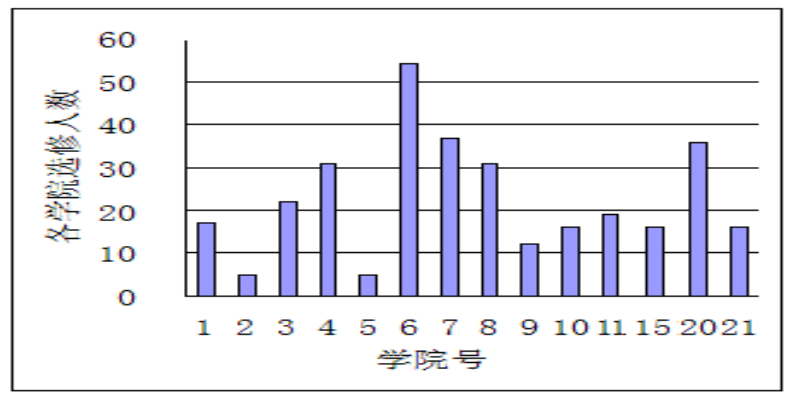

FIGURE I. NUMBER OF ELECTIVE COURSES IN VARIOUS COLLEGES DIAGRAM

From this diagram, the diverse degree of desire for nonelectrical knowledge among the students can be seen, especially marine engineering, power and energy, electrical, chemical, nuclear and software is particularly fond of the course content.

At present, our school has been continuing using the main course content and teaching methods which are established in 1997, 24 hours teaching hours, there is no corresponding experimental facilities. Using a blackboard in lectures makes students lack perceptual knowledge of computer hardware systems, in the past year to do some exploring Instructor research, take a multimedia laboratory instruction, a small increase in the experiment, summarizes some experience teaching effect had some improvement, but also found some problems. While teaching content is too specialized and outdated, computer technology is developing rapidly, resulting in various forms of computer system architecture could not be well integrated into the classroom, especially in the core of the microcomputer 8086 randomly selected five textbooks published by Higher Education Press, Machinery Industry Press and China Railway Publishing House in 2005 including reprint version. Through statistics, three textbooks have more content on Intel 8086 series processor instructions and interface structure, which contains four more assembly language knowledge. However, Intel 8086 assembly language and knowledge for the low-grade non-computer background students[2] are too hard and boring, not intuitively reflecting the hardware knowledge, low-grade non-computer background students are difficult to understand, difficult to master.

University lacks of experimental environment and supporting materials, as the course is highly experimental demanded curricula and excessive students select the hardware course, so there is no specific laboratory space, equipment and teachers accompanying the students to master thorough enough. Textbook selection is too professional. Currently, the official publication of textbooks, both computer hardware technology base and microcomputer principle \& interface technology, are still about computer science $80 \times 86$ assembly language and programmable interface chips. There is no combination of 
computer hardware and new products of nearly 10 years new technologies development. Because of non-computer background students, this highly specialized content is difficult to meet the students' learning expectations. In addition, this course system is not complete, management is too backward [3] 65. Our school non-electric Majors did not offer relevant "digital circuit" course, originally established by the teaching content for sophomores and juniors, and now the elective course students are mainly freshman and sophomore, which is not conducive to knowledge learn and master. Therefore, the course in the teaching system, teaching content, teaching methods, teaching material construction, the experiments and curriculum management urgently need for deep reform and improvement.

\section{REFORMATION IDEAS AND RESEARCH}

\section{A. Selecting Constucion of Logic Thinking and Computing Instruction}

Domestic universities have proposals for reform of the curriculum, which Beijing Institute of Technology Basic Computer Courses Song-day team, LI Feng-xia and other teachers make a full investigation of the course on the basis of the current status, in 2010, they carry out new teaching reformation. The core idea is to help students to overcome the fear of hardware, computer hardware classical techniques and new developments as the main content, secondary openness and freedom of experimental teaching platform, focusing on curriculum reform experiments, and have achieved some results. Basic Computer Courses Guofangkeda team Li, and other teachers for the course Zou Fengxing proposes the use of "problem-oriented teaching" strategies (Problem Based Learning, PBL, also known as "problem-based learning"), the overall design, to carry out multi-angle Teaching a full range of research, and achieved certain results.

Combined with my current teaching school system and teaching content, primarily for sophomore learning more noncomputer majors and master content: basic logic circuit, with its basis, into the concept of computational thinking, so that students perceive computers and computing principles solution to the problem; in today's applications are very popular microcomputer basic structure of the main line, combined with a typical case of progressive approach to expand the application system; with multimedia teaching laboratory environment, the use of model simulation and experimental program to allow students to fully grasp the microcomputer hardware features of the system, in order to achieve the purpose of teaching. The main contents are as follows.

March 2006, Carnegie Mellon University Computer Science Department - Jeannette Wing (Jeannette M. Wing) Professor of "Communications of the ACM " magazine shows and defined computational thinking. Zhou said: computational thinking is the use of the basic concepts of computer science for problem solving, system design, human behavior understanding and other activities which are covering a range of thinking of computer science [4] 1. Computer hardware technology is to establish the nature of the computer system architecture on the basis of logic operations. Also, computational thinking draws on general mathematical thinking problem solving methods, the general thinking draws on engineering design and evaluation methods of large and complex real world systems. Besides, it still draws on complex general scientific thinking, intelligence, psychology, human behavior understanding and so on. Computational thinking builds on the capabilities and limitations of the calculation process, performed by a machine. Calculation methods and models enable us to deal with those who had the courage to not be solved problems and not to be designed system independently by individuals.

Computer basic logic operations is also known as mechanical operations, including AND, OR, NOT and XOR, thereby, constituting the boolean operation basic device on the basis of the computer by the : decoders, registers, counters, arithmetic unit, a combination of logic operation and computational thinking through methods of reduction, embedding, transformation and simulation makes seemingly difficult problem into a reinterpretation about which we know how to solve the problem. That method is an effective way to calculate a combination of thinking and logic operations. The appearance of computer spawns intelligent thinking which upgrades computer from the tool to the development of thinking and basic importance to "read, write, count" the same as the "a common understanding and a class of universal skills "and also means that the computer science from the leading edge to the base of high-end universal transformation [4] 2. At the same time, method of how to effectively combine technology and computer hardware, such as recursive computational thinking, parallel processing, coding data translation into code, made an important research content in the future teaching.

\section{B. Establish the Strutured Mainline of Microcomputer Hardware}

Current teaching content of computer hardware technology courses generally lag behind no matter computer hardware technology base or microcomputer principle and interface technology, content is still taught in computer science 80x86, assembly language, programmable interface chips and other content-based. For non-electric Majors college students, the content is too abstract, logical is too strong, it will be difficult to understand. In addition, there is no according physical hardware combined with a lot of knowledge, which makes learning boring. Because of course facing non-computer science background students, this highly specialized content is difficult to meet the students' learning expectations. Throughout the five years newly related published textbooks, teaching content is almost the same as the contents taught 10 years ago (2000 or so) [2] 116.

Establish a microcomputer-based system architecture, MPU (microprocessor)-based structure of the core extended memory, external interface, constituting a simple system architecture; learning from Harbin University of Industry "Computer Hardware Technology" syllabus, starting from simple structure and easy simulation to implement SCM structure experiments, combining the characteristics of our school, the system progressively becomes more complicated until today's new technologies of quad-core architecture introduction . Featured typical microcomputer system architecture case with a detailed analysis of the teaching make students master the basics while 
broadening their horizons. How to establish a professional nonelectrical "Computer Hardware Technology" curriculum raises an important teaching content for our study in the future.

Practice teaching is an important part of higher education courses, which is the only way must be passed from passive learning to active learning. In the "Computer Hardware Technology" course, practical ability is particularly important. Characteristics of teaching hardware determine that it demands more equipment, funds, investment and teaching stuff than software programs. At first, our school has some experimental course, the main contents are dismantling, assembly and breakdown maintenance, etc.,however, because of limited student level, providing eliminated or scrapped machine, the failure rate is very high coupled with the increasing number of students, so the experiment lasted only three sessions then it was forced to be canceled.

With the continuous improvement of the teaching targeting level, expanding of teaching content and the improving of multimedia teaching and learning environment, the computer hardware technology of simulation becomes possible. After a year experience of teaching with multimedia laboratory, it showed that the use of a variety of teaching methods of multimedia laboratories makes it available for them to find the best way of expression through electronic lesson plans, physical projection, animation lecture slides, virtual circuits and EDA design. Besides, it offers more forms of teaching content, improving teachers' teaching effectiveness to enhance students' perceptual knowledge. How to extract non-electrical professional "computer hardware technology base" experimental curriculum and how to complete a high level of experiment and simulation lecture slide raise an issue for further discussion in the future.

In the range of universities which create such a basic computer course, such as Microcomputer Principle and Interface Technology curriculum, they often offer computer classes by professional teachers, not belong to basic computer education category. Non-college students learning computer hardware technology power class has formed a barrier. In the course content, questioned point among the existing hardware technology curriculum system concentrated in: Course positioning is not clear, it is difficult to implement the hours, do not have the experimental conditions, the lack of appropriate teaching materials and so on. Throughout the five years of the new publishing-related materials, most of the teaching content remain consistent as 10-years-ago materials(2000 or so)[2], the teachings of the overall construction ideas still remain in the teaching of computer principle stage, can not reflect today's computer miniature technology, hardware integration and tools development trend [5].

On the basis of summarized 34 textbooks published after 2005 about teaching this course, it is suggested that the hardware course should be combined with the actual situation of computer courses. As results, 32 teaching hours (6 to 10 Experimental Hours) is appropriate, and moderately extended to 54 hours and experimental hours extended to 12 hours (experimental Hours 25 percent of the total hours) could be possible. This design of teaching form is conducive for each university as the school public elective courses, general education classes, courses and other forms of experimental arrangement related in the syllabus [3] 66.

While strengthening the Construction materials, the management of elective students also directly impact the teaching effect, the strict control of a college freshman elective courses, besides, try to limit the power class students junior and senior year of college to take the course, to avoid duplication of knowledge and learning. Encourage college students to participate in research projects of teachers, organizing various computer hardware class practice group, try to practice with the instructor and the environment, students develop the interest and enthusiasm to achieve good teaching results.

\section{CONCLUSION}

Universities for non-computer professional computer hardware foundation course construction technology is an important and difficult problems in recent years. Affected by many factors, some universities had to give up teaching the hardware courses. Meanwhile, the national first class Polytechnic universities pay much attention to students' integrated ability of computer, in that case, universities provide diverse opportunities and conditions to the reform program, and gradually formed its own unique teaching system. Teaching reformation is an arduous process of exploration and constant practice, teachers and students not only just need mutual understanding and cooperation, but also need the support of the leadership and encouragement. Through continuous reform and improvement of the curriculum, will make comprehensive use of the computer system's overall ability among our college students improved.

\section{ACKNOWLEDGMENT}

This study by the Institute of Higher Education Reform Project of Heilongjiang Province (project number: HGJXHB2110344), funded Harbin Engineering University Teaching Education Research Project in 2013.

\section{REFERENCES}

[1] Fengxia Li and Dandan Song, Computer hardwaretechnology base course material analysis and construction[J], Computer Education,2011(16), pp.116-118.

[2] Tian Song,Fengxia Li, “ Computer hardware technology foundation curriculum reform experiment”[J] Computer Education ,2010,Vol 16,pp.65-66

[3] Yizhen Zhou,Computing Thinking[C]. Chinese Society of the Ministry of Science and Technology Association , 2007,pp.111-112.

[4] Linyang Sheng and Liping Li. Applied Talents positioning hardware computer science teaching reform [J]. Computer Education.2010,Vol 22,pp.39-42

[5] Weijiang Wu and Jianhui Zhao. Also on computer hardware Curriculum Construction [J].Computer Education.2012,Vol 1,pp.24-27. 